\title{
Comparison of ground motions estimated from prediction equations and from observed damage during the $M=4.61983$ Liège earthquake (Belgium)
}

\author{
D. García Moreno and T. Camelbeeck \\ Royal Observatory of Belgium, Avenue Circulaire 3, 1180 Brussels, Belgium \\ Correspondence to: D. García Moreno (david.garciamoreno@oma.be)
}

Received: 28 September 2012 - Published in Nat. Hazards Earth Syst. Sci. Discuss.: Revised: 3 May 2013 - Accepted: 8 May 2013 - Published: 7 August 2013

\begin{abstract}
On 8 November 1983 an earthquake of magnitude 4.6 damaged more than 16000 buildings in the region of Liège (Belgium). The extraordinary damage produced by this earthquake, considering its moderate magnitude, is extremely well documented, giving the opportunity to compare the consequences of a recent moderate earthquake in a typical old city of Western Europe with scenarios obtained by combining strong ground motions and vulnerability modelling.

The present study compares $0.3 \mathrm{~s}$ spectral accelerations estimated from ground motion prediction equations typically used in Western Europe with those obtained locally by applying the statistical distribution of damaged masonry buildings to two fragility curves, one derived from the HAZUS programme of FEMA (FEMA, 1999) and another developed for high-vulnerability buildings by Lang and Bachmann (2004), and to a method proposed by Faccioli et al. (1999) relating the seismic vulnerability of buildings to the damage and ground motions. The results of this comparison reveal good agreement between maxima spectral accelerations calculated from these vulnerability and fragility curves and those predicted from attenuation law equations, suggesting peak ground accelerations for the epicentral area of the 1983 earthquake of $0.13-0.20 \mathrm{~g}$ ( $\mathrm{g}$ : gravitational acceleration).
\end{abstract}

\section{Introduction}

Evaluating the impact of future earthquakes in terms of damage and victims is one of the main objectives of applied research in earthquake seismology and seismic engineering.
Roughly, two main steps are considered in such analysis. The first one consists of evaluating the strong ground motions produced at specific sites by a given earthquake characterized by its location, depth, focal mechanism and magnitude. Secondly, the state of damage of particular buildings can be estimated using fragility or vulnerability curves expressing the destructiveness in function of the ground motion characteristics. In seismically active regions worldwide, ground motion prediction equations (GMPE) and fragility curves have been established based on an appropriate feedback from measurements and observations done at the occasion of recent destructive earthquakes (e.g. Kircher et al., 1997a). In plate interiors, where seismic activity is moderate and large earthquakes are rare, this feedback is seldom possible because most destructive earthquakes usually occurred before the development of modern seismic or accelerometric networks. In most cases the only available information to validate the seismic risk and hazard evaluations of these regions comes from historical earthquakes, for which no information exists on the associated strong ground motions and their relationship with the intensity of the damage. This is the situation in most parts of Western Europe, particularly in Belgium and the neighbouring regions (Camelbeeck et al., 2000), where two recent moderate earthquakes that occurred in Liège on 8 November $1983\left(M_{\mathrm{S}}=4.6\right)$ and Roermond (the Netherlands) on 13 April $1992\left(M_{\mathrm{S}}=5.4\right)$, which combined damages exceeded 100 million euros at the time of their occurrence, demonstrated the high seismic vulnerability of the old cities of Europe (Plumier, 1985; Berz, 1994; Pappin et al., 1994; Plumier et al., 2006). 
In Belgium, the lack of direct measurement of the strong ground motions associated with the most recent destructive earthquakes is compensated by the detailed information available on the damage produced by them. In particular, the damage caused by the 1983 Liège earthquake was especially well documented: detailed information exists on the damage caused to the 16000 houses for which the owners asked for a contribution from the Belgian State to meet the repair costs. These data are stored in the Belgian Calamity Centre and was the main source of information used in the works of Jongmans and Campillo (1984), Plumier et al. (2006) and the seismic risk report of Jongmans and Plumier (2000). The completeness of the damage dataset available for the 1983 Liège earthquake is unique for Western Europe and provides a good opportunity to compare the consequences of moderate magnitude earthquakes in a typical old city of Western Europe with the scenarios proposed by ground motion predictions and vulnerability evaluations.

The present study intends to evaluate the possible ground motions produced by the 1983 earthquake in the region of Liège from the intensity of the damage caused to the buildings located in this area in order to compare them with the horizontal accelerations predicted by GMPEs for earthquakes of similar source characteristics. To obtain the accelerations from the intensity of the damage, we have applied three different methodologies: two fragility curves constrained for low-rise unreinforced brick-masonry buildings extracted from the works of Lang and Bachmann (2004) and Ebel (2006), and a vulnerability-indexed methodology developed by Faccioli et al. (1999), which was already adapted to the building typologies of Liège by Jongmans and Plumier (2000). To conduct this investigation, we compiled a vast dataset on the local damage produced by the 1983 Liège earthquake by combining some of the original files collected by the Belgian Calamity Centre after the earthquake with detailed information gathered in official reports performed by national and regional organizations, research institutions and universities.

\section{The 1983 Liège earthquake}

On 8 November 1983, the earth trembled at 00:49 UTC in the region of Liège (eastern Belgium), rudely awakening the population in a radius of more than $30 \mathrm{~km}$. The tremor was so strong that many people were frightened and went down to the streets; some of them spent the rest of night outdoor due to the heavy damage caused to their houses. The main shock was followed by two aftershocks that were weakly felt in the region of Liège at 01:24 UTC $\left(M_{\mathrm{L}}=2.9\right)$ and 02:13 UTC $\left(M_{\mathrm{L}}=3.5\right)$ of the same day (e.g. Camelbeeck, 1985). The consequences of this earthquake were unusual considering its "low" magnitude $\left(M_{\mathrm{S}}=4.6\right.$ and $\left.M_{\mathrm{L}}=5.0\right)$ : a huge problem of inhabitant evacuation and of rescue lodgement (more than 1000 homeless), two direct victims and many injured, and 16000 houses damaged at different grades (De Becker, 1985; Plumier et al., 2006). The significant damage produced locally by this seismic event, which reached seismic intensities of VII (Fig. 1), has been attributed to its shallowness and the possible amplification of the ground shaking due to the local geology and the consequences of former mining activity on the ground surface, which was already affecting some of the buildings located in this area (Jongmans and Campillo, 1984; Monjoie, 1985; Jongmans, 1989; Jongmans and Plumier, 2000). This appears to be corroborated by the damage distribution as the largest damages seem to have coincided with places close to old mines and where colluvium and/or alluvium sediments reach significant thickness (see Jongmans and Campillo, 1984; Jongmans, 1989). Indeed, these two factors combined with the high seismic vulnerability of the building stock of this region, which is characterized mainly by old low-rise masonry buildings sharing two walls, should have influenced strongly the damage produced by this earthquake (Jongmans and Plumier, 2000; Plumier et al., 2006).

The source of the 1983 earthquake has been located by Ahorner and Pelzing (1985), with an uncertainty of $\sim 2 \mathrm{~km}$, at $50.63^{\circ}$ latitude $\mathrm{N}, 5.52^{\circ}$ longitude E (Fig. 1) and focal depth of $\sim 6 \mathrm{~km}$. They also evaluated the seismic moment released by this seismic event according to seismic stations located in Germany obtaining $\sim 1.2 \times 10^{23} \mathrm{dyn} \mathrm{cm}$. In a later work, Camelbeeck (1993) determined its focal mechanism using $P$-wave first motion from local and regional stations interpreting it as dextral strike-slip motion with a small reverse component along a $\mathrm{N} 245^{\circ} \mathrm{E}$ striking fault dipping $76^{\circ}$ to the north. Considering the location and characteristics of the 1983 earthquake and the seismicity of this region, Camelbeeck (1993) proposed the St Gilles-Marie-Seraing fault system as the most probable seismogenic source of this event (see Fig. 2 for location). The ground motions affecting the region of Liège during this earthquake are presently unknown, although some rough estimations exist based on the earthquake characteristics and/or the damage produced by it. For instance, Plumier (1985) suggested peak ground accelerations (PGA) for the epicentral area of 0.15 to $0.2 \mathrm{~g}$ on the basis of several tombs knocked down or moved during the earthquake in a cemetery located nearby the earthquake epicentre. These PGA are not far from those estimated by Camelbeeck (1985) from the dynamic parameters of the 1983 earthquake, who proposed PGA around $0.13 \mathrm{~g}$ for the epicentral area of this event.

\section{The damage dataset}

At the time of the Liège earthquake, different regional and federal organizations collected information on the damage with the objective of informing the emergency services where fast technical interventions for public safety were needed (securing damaged chimneys, shoring of walls, etc.) 


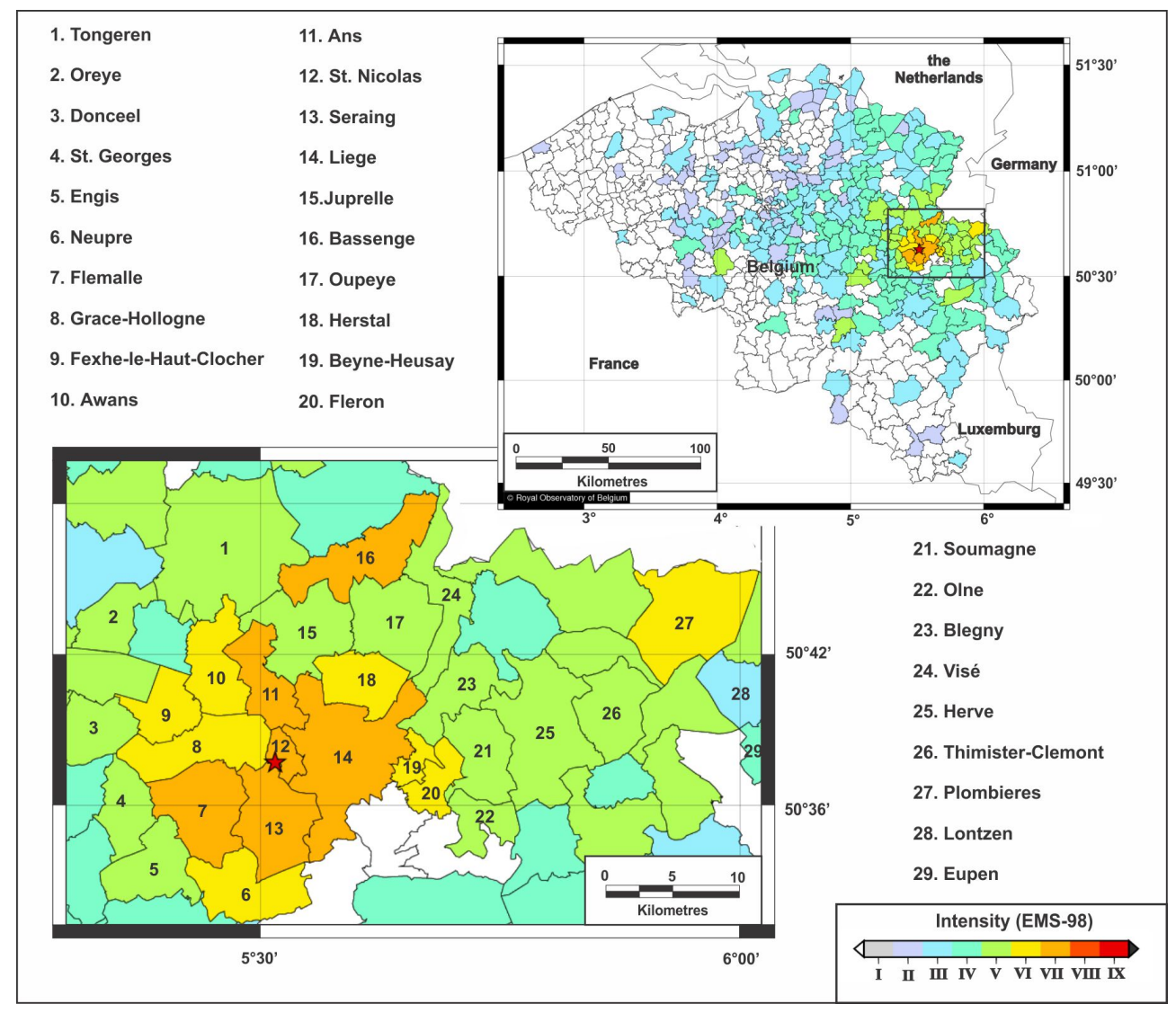

Fig. 1. Macroseismic map of the 1983 Liège earthquake (http://seismologie.oma.be). The black rectangle indicates the region of interest in the present study, which coincides with the most damaged localities. The numbers indicate the names of the different localities of this region. Red star: earthquake epicentre.

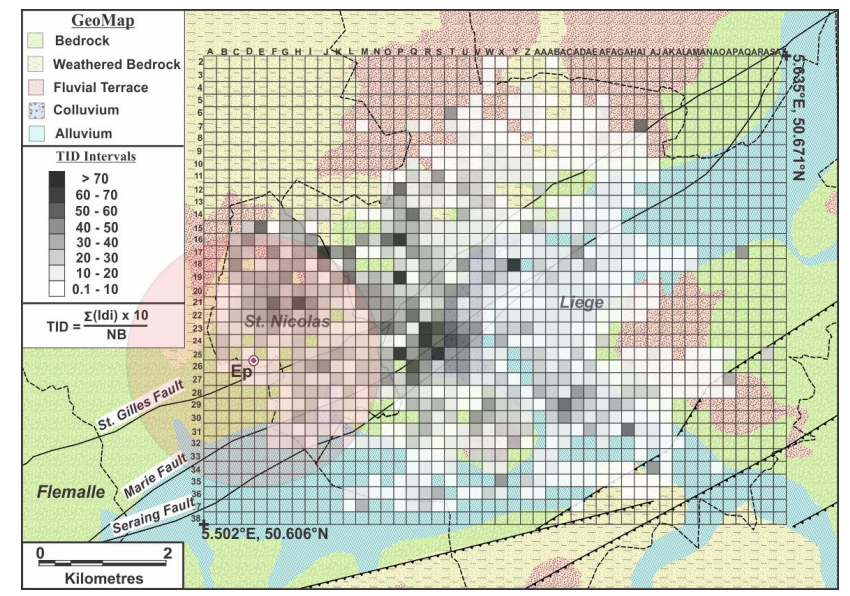

Fig. 2. Geographical distribution of the total damage index or TID over Liège and Saint Nicolas localities according to the PSE-UL report. $\mathrm{Id}_{i}$ : damage index; $\mathrm{NB}$ : total number of buildings per square area; Ep: epicentre; red circle: epicentre uncertainty. Numbers and letters represent the coordinate system of the grid. and establishing a list of the people for which public help was required. A few weeks after the earthquake, the Belgian Government decided to reimburse part of the repair costs and invited the owners from the most affected localities to report the damage on their properties. The owners of 16000 houses answered the government call, sending detailed reports on the damage that affected their properties over to the Belgian Calamity Centre. All these individual files were controlled and completed by government experts, who compiled all the information in a database created for that purpose. Unfortunately the informatics structure of that database has not been preserved to the present day; therefore only the paper copies of those documents are presently available. The lack of a database structure makes it a titanic task to recover all the original files containing damage information on the 1983 earthquake, for thousands of documents about this and other natural catastrophes are stored in the Belgian Calamity Centre. Consequently, the present study has been mainly based on data compiled in several official reports performed after the earthquake, most of them based on or part of the original information stored at the Belgian Calamity 
Centre. In total, five main sources of information were used in this study:

1. Since 1932, whenever an earthquake is felt in Belgium, the Royal Observatory of Belgium (ROB) sends a standard questionnaire to the authorities of all Belgian localities. This document consists of several simple questions (see De Becker, 1985) aiming to evaluate the macroseismic intensity of each affected locality (Fig. 1). The most interesting information for the purpose of the present study contained in these formularies is the percentage of damaged chimneys per locality. This document was especially useful for characterizing the damage that occurred in the localities for which no information was found on the damage caused to individual buildings.

2. The regional fire brigade, in its report Rapport d'Habitabilité de Logements Sinistrés, established a list of all the buildings they visited just after the 1983 earthquake, specifying in each case if an intervention of an emergency agency was needed due to heavy damage on walls, roofs or chimneys, risk of CO leaks, fire and/or the possibility of collapsing buildings. According to this report, 1750 of the visited buildings presented some kind of damage, 168 of which were declared uninhabitable and 37 were marked to be demolished due to the intense damage on their structure (see De Becker, 1985; Plumier et al., 2006). A copy of the original report was sent to the ROB after the earthquake and it has been used in this study for the evaluation of the damage caused to the buildings situated in the locality of Saint Nicolas (see Fig. 1 for location).

3. A document provided to the ROB after the earthquake by the authorities of the locality of Flémalle (see Fig. 1 for location) consisting of 212 pages with brief descriptions of the damages caused by the 1983 Liège earthquake to the 686 buildings damaged in that locality during this seismic event.

4. An unpublished post-seismic evaluation of the damage that occurred in the localities of Saint Nicolas and Liège performed during the months that followed the 1983 earthquake by D. Jongmans (University of Liège), report which will be referred to as PSE-UL in the following sections of this paper. This work was based on the information gathered by the Belgian Calamity Centre concerning the state of damage and repair costs of the damaged buildings situated in the localities of Saint Nicolas and Liège. Unfortunately, the information concerning individual damaged buildings located in Liège has been lost. The only data recoverable from that work is the information regarding the 3461 damaged buildings located in the district of Saint Nicolas. These data include the addresses of the damaged buildings, their
Table 1. Codes defined for the calculation of the damage index (Id) by the authors of the PSE-UL report to evaluate the damage of the buildings affected by the 1983 earthquake.

\begin{tabular}{lccc}
\hline $\begin{array}{l}\text { Damaged } \\
\text { feature }\end{array}$ & $\begin{array}{c}\text { No } \\
\text { damage }\end{array}$ & $\begin{array}{c}\text { Slight } \\
\text { damage }\end{array}$ & $\begin{array}{c}\text { Significant } \\
\text { damage }\end{array}$ \\
\hline Chimney & 0 & 1 & 1 \\
Roof & 0 & 2 & 3 \\
Internal walls & 0 & 1 & 3 \\
External walls & 0 & 2 & 4 \\
Floor and ceiling & 0 & 1 & 3 \\
Fragile elements & 0 & 1 & 2 \\
\hline
\end{tabular}

repair cost (RC), number of floors, surface in square metres, age and relative location (house in a row, in a corner, isolated, etc.). The authors of the PSE-UL report quantify the intensity of the damage caused to the buildings using a damage index (Id) consisting of the addition of several codes representing the state of damage of different features (Table 1). The intensity of the damage at different locations is illustrated in this report in two maps showing the distribution of the total repair cost (TRC) and total damage index (TID) over a grid dividing Liège and Saint Nicolas into squares of $200 \mathrm{~m} \times 200 \mathrm{~m}$ (Figs. 3 and 4). These two maps are presently the only available information on the damage caused to the 4959 damaged buildings situated in the locality of Liège.

5. Several paper files collected from the Belgian Calamity Centre by the Royal Observatory of Belgium during the last years. These files contain brief descriptions of the repairs that 113 buildings situated in different Belgian localities needed due to the 1983 earthquake, in addition to information similar to the one presented in the PSE-UL report: repair cost, number of floors, features damaged (chimney, external walls, etc.) and year of construction. These data have been complemented with an estimation of the degree of damage for each of the 113 buildings according to the European Macroseismic Scale EMS-98 (Grünthal et al., 1998) based on the descriptions of the repairs included in these documents.

\section{Fragility curves and vulnerability index}

\subsection{Fragility curves}

The seismic fragility curve of a building represents the probability of exceeding a damage state or degree of damage for a given ground motion intensity (Kircher et al., 1997a). Fragility curves are usually expressed as cumulative normal or lognormal distributions relating damage and level of shaking for specific seismic vulnerability classes. These curves 
Table 2. Buildings typically found in the region of Liège according to Jongmans and Plumier (2000).

\begin{tabular}{|c|c|c|}
\hline Type of house & Age & Description \\
\hline Modest house & $\begin{array}{l}\text { Mid-19th-beginning } \\
\text { 20th century }\end{array}$ & $\begin{array}{l}\sim 40 \mathrm{~m}^{2} \text { per floor brick-masonry house aligned with the street in groups of } \\
\text { buildings sharing one or two walls, usually presenting two levels (one storey), } \\
\text { and two-sided steeply pitched tile roof. Presence of elongated doors and win- } \\
\text { dows and sometimes ornamental motives on the façade. }\end{array}$ \\
\hline Average house & $\begin{array}{l}\text { End } 19 \text { th-beginning } \\
\text { 20th century }\end{array}$ & $\begin{array}{l}60-80 \mathrm{~m}^{2} \text { per floor brick-masonry house aligned with the street in groups of } \\
\text { buildings sharing one or two walls, usually presenting } 3-4 \text { levels ( } 2-3 \text { storeys), } \\
\text { two-sided pitched tile roof, large doors and windows, presence of balconies and } \\
\text { others ornamental motives on the façade (projecting cornice, etc.). }\end{array}$ \\
\hline $\begin{array}{l}\text { Maison de Maitre } \\
\text { (Elegant townhouse) }\end{array}$ & $\begin{array}{l}\text { End } 19 \text { th-beginning } \\
\text { 20th century }\end{array}$ & $\begin{array}{l}80-120 \mathrm{~m}^{2} \text { per floor brick-masonry building aligned with the street and shar- } \\
\text { ing one or two walls, usually presenting } 3-5 \text { high ceiling levels ( } 2-4 \text { floors), } \\
\text { tile roofs with two or more sloping sides, very large doors and windows, pro- } \\
\text { jecting cornice, presence of balconies and façade built in bricks covered with } \\
\text { ornamental rocks or other decorative materials. }\end{array}$ \\
\hline Historic house & 18th-19th century & $\begin{array}{l}40-100 \mathrm{~m}^{2} \text { per floor brick-masonry building usually located in the historical } \\
\text { centre, sharing one or two walls. Three to four levels ( } 2-3 \text { floors) slate roofs, } \\
\text { presence of ornamental rocks on the façade, high narrow windows and doors. }\end{array}$ \\
\hline Modern house & 1930-present day & $\begin{array}{l}60-100 \mathrm{~m}^{2} \text { brick-masonry building with garage or/and ground floor semi- } \\
\text { underground (sub-basement). Usually located outside the city centre sharing } \\
\text { one or two walls. Three to four levels ( } 2-3 \text { floors), presence of flat roofs, wide } \\
\text { windows and mix brick-rough stone façades. }\end{array}$ \\
\hline Rural house & $\begin{array}{l}\text { 19th-beginning } \\
\text { 20th century }\end{array}$ & $\begin{array}{l}\sim 100 \mathrm{~m}^{2} \text { isolated brick-masonry building presenting tiles or slate two-sided } \\
\text { steeply pitched roofs. Two levels ( } 1 \text { floor), windows and doors generally em- } \\
\text { bedded in rocks and façade in bricks or rough stones. }\end{array}$ \\
\hline Apartments & $1940-$ present day & $\begin{array}{l}\text { Large mix brick-reinforced concrete building with } \geq 5 \text { floors (individual apart- } \\
\text { ments), wide windows and flat roof. }\end{array}$ \\
\hline
\end{tabular}

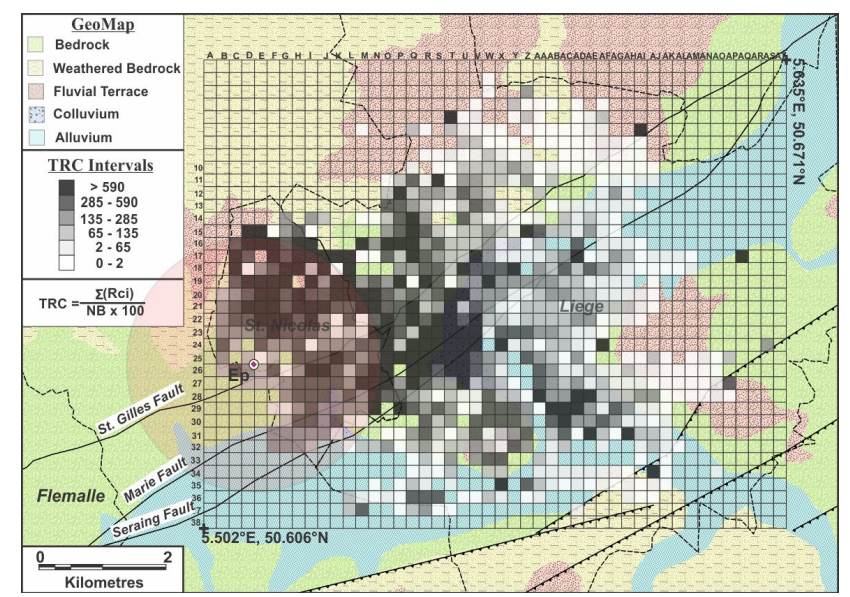

Fig. 3. Geographical distribution of the total repair cost (TRC) over Liège and Saint Nicolas localities according to the PSE-UL report. $\mathrm{RC}_{i}$ : repair cost of individual buildings; $\mathrm{NB}$ : total number of buildings per square area; Ep: epicentre.

are generally constrained from direct observations from past earthquakes (e.g. Spence et al., 1992) or the analysis of mechanical models (e.g. Lang and Bachmann, 2004). Fragility curves are mostly used to estimate the possible damage state which buildings of different vulnerability classes will present after being subjected to ground shaking. An alternative of this approach might be the application of fragility curves to establish the relationship between the amount of buildings of a particular type (vulnerability class) presenting a similar state of damage and the intensity of the ground motions that damaged them (e.g. Lang and Bachmann, 2004; Kochkin and Crandell, 2004; Ebel, 2006). Thus, knowing the percentage of buildings of a particular vulnerability class presenting a given degree of damage, it should be possible to approximate the intensity of the ground motions that affected that region by applying a fragility curve appropriate for that area and vulnerability class (e.g. Ebel, 2006).

In the present study, we intend to apply the aforementioned methodology to estimate the ground motions produced by the 1983 Liège earthquake in several Belgian localities according to the damage caused to the building stock existing in them. Unfortunately, there is no fragility curve designed specifically to model the response of the building stock of Liège to ground shaking, and therefore we were forced to use fragility curves developed for other regions with similar types of buildings. Several fragility curves were proposed as candidates to model the damage-ground motion relationship 
a)

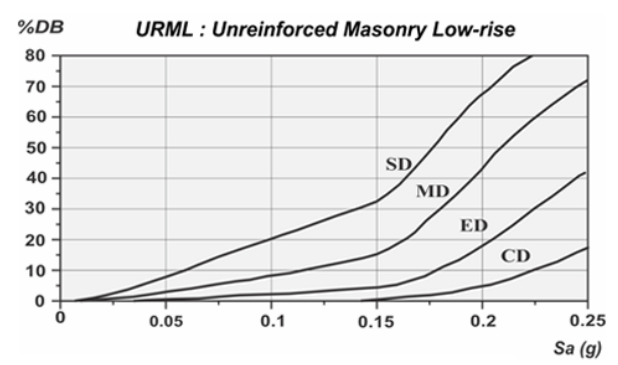

b)

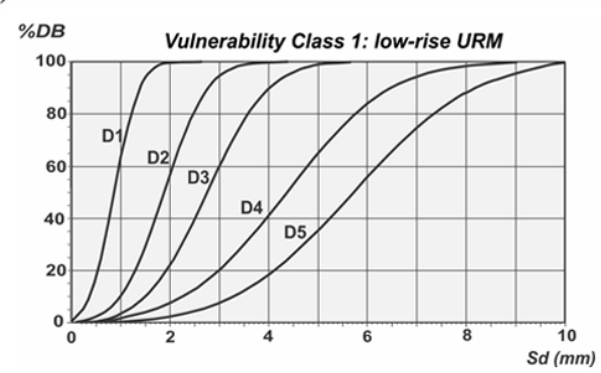

c)

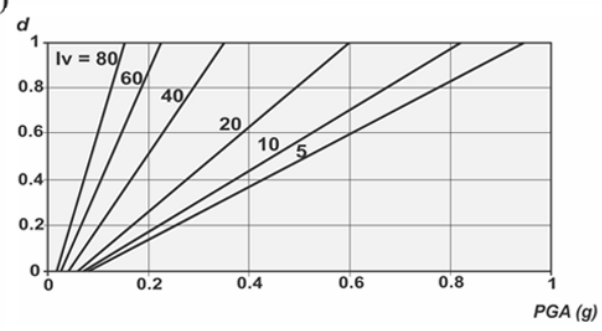

Fig. 4. Fragility and vulnerability curves. (a) and (b) HAZUS (Ebel, 2006) and Bsl (Lang and Bachmann, 2004) fragility curves; (c) relationship of vulnerability-damage-peak ground acceleration (PGA) according to Faccioli et al. (1999). DB: percentage of damaged buildings; $\mathrm{Sa}$ : spectral acceleration; $\mathrm{Sd}$ : spectral displacement; PGA: peak ground acceleration.

in the region of Liège: the one discussed in Ebel (2006) created by the HAZUS programme of FEMA (Kircher et al., 1997a; FEMA, 1999), those proposed by the RISK-UE project (RISK-UE BEE special edition, 2006), and the curves discussed in the works of Spence et al. (1992), Rota et al. (2010) and Lang and Bachmann (2004). After analysing all of them in detail, we decided that the HAZUS and the class 1 fragility curve from Lang and Bachmann (2004) were the ones that best matched the building stock existing in the region of Liège. Ebel (2006) discusses the application of the HAZUS fragility curve to houses built in the 17th and 18th century located in the eastern United States, buildings which are generally characterized by two/three-storey brick-masonry structures with timber floors. However, the selected fragility curve from Lang and Bachmann (2004) was designed to model the damage-spectral displacement relationship for buildings constructed before 1940 located in the region of Basel (northern Switzerland), which they classified as vulnerability class 1 : low-rise (1-3 stories), unreinforced masonry buildings with timber floors. Both vulnerability classes coinciding with the kind of construction typically built in central and northern Europe before 1940-1950, which are indeed the most abundant buildings in the region of Liège (Jongmans and Plumier, 2000). There, a typical masonry building consists of a small $\left(40-100 \mathrm{~m}^{2}\right)$ unreinforced brick construction sharing one or two walls with buildings nearby, and mostly built during the end of the 19th century to the beginning of the 20th (Table 2). This is corroborated by the PSE-UL report, where it is observed that $\sim 94 \%$ of the buildings damaged by the 1983 earthquake located in
Saint Nicolas have less than 3 storeys. It has also been noticed that $50 \%$ of the houses listed in that report were built before 1920. In fact, only $\sim 15 \%$ of the damaged buildings were built after 1960. Consequently, it can be assumed without much error that the buildings damaged by the 1983 Liège earthquake will most probably belong to the vulnerability classes of pre- and low-code URML according to the HAZUS programme (Kircher et al., 1997a) and class 1 according to Lang and Bachmann (2004). We can then suppose a natural period for a typical building located in this area of $\sim 0.3 \mathrm{~s}$.

Both selected curves should thus be compatible with the building stock of our study area; however, they appear to be quite different from each other. On the one hand, the HAZUS fragility curve establishes the relationship between the percentage of low-rise unreinforced masonry buildings (URML) in a specific degree of damage and the spectral accelerations (Sa) capable of producing such damage assuming a natural period of 0.1-0.3 s (Fig. 4b). The Lang and Bachmann (2004) one (in this study referred to as Bsl), on the other hand, shows the correlation between the percentage of damaged URML buildings and the spectral displacement associated with them, considering natural periods between 0.2 and $0.8 \mathrm{~s}$. This difference has been retained by converting Sd to Sa for natural frequencies $(F)$ of $3.3 \mathrm{~Hz}$ applying Eq. (1) (Newmark and Hall, 1982):

$\mathrm{Sa}=\operatorname{Sd}(2 \pi F)^{2}$.

Another difference is that neither of them uses the same damage scale to define the damage states of the buildings. 
Table 3. Vulnerability index defined for the different types of buildings located in the region of Liège (Jongmans and Plumier, 2000; Plumier et al., 2006).

\begin{tabular}{|c|c|c|c|c|c|c|c|c|}
\hline Type of Building & Basic Iv & HPOS & LRGF & $\mathrm{HB}$ & SL & IS & $\mathrm{RH}$ & AR \\
\hline \multicolumn{9}{|l|}{ LR brick masonry built before 1940} \\
\hline Isolated or sharing two walls & +42 & +5 & +5 & +5 & +5 & +5 & +5 & -15 \\
\hline End of a row or in a corner & +52 & +5 & +5 & +5 & +5 & +5 & +5 & -15 \\
\hline \multicolumn{9}{|l|}{ LR brick masonry built after 1940} \\
\hline Isolated or sharing two walls & +17 & +4 & +4 & +4 & +4 & +4 & +5 & -10 \\
\hline End of a row or in a corner & +28 & +4 & +4 & +4 & +4 & +4 & +5 & -10 \\
\hline \multicolumn{9}{|l|}{ Buildings with more than five storeys } \\
\hline Mix masonry-reinforced concrete & -5 & +10 & +5 & +20 & +10 & +20 & +5 & \\
\hline Modern reinforced concrete & -20 & +10 & +5 & +20 & +10 & +20 & +5 & \\
\hline
\end{tabular}

LR: Low-rise; HPOS: high percentage of open spaces (e.g. large windows); LRGF: low resistant ground floor (e.g. shop windows, columns, etc.); HB: heavy balconies; SL: slenderness; IS: irregular structure; RH: risk of hammering due to very close adjacent buildings; AR: additional reinforcements (chains, diaphragms, etc.).

The HAZUS fragility curve consists of four curves corresponding to the median values of the normal distribution correlating percentage of damage and spectral acceleration for slight (SD), moderate (MD), extensive (ED) and complete (CD) damages. However, the Bsl one comprises five curves defining the median values that correlate percentage of damaged buildings with spectral displacement for the damage states defined by the European Macroseismic Scale (Grünthal et al., 1998; Grünthal and Levret, 2001): D1, D2, $D 3, D 4$ and $D 5$. In the present study, the equivalences between these two damage scales have been taken from those proposed by Hill and Rossetto (2008), who concluded that $\mathrm{SD}, \mathrm{MD}, \mathrm{ED}$ and CD from the HAZUS damage scale correspond, respectively, to $D 1, D 2, D 3$ and $D 4$ plus $D 5$ of the EMS-98 one.

\subsection{Vulnerability index}

The differences in intensity of the damage caused to buildings of similar characteristics exposed to the same ground shaking are usually due to differences in their shape, material, location with regards to others, age, etc. (e.g. Murty, 2005). These parameters define the seismic vulnerability of a building and can be quantified using a vulnerability index (e.g. Faccioli et al., 1999). According to Faccioli et al. (1999), the peak ground acceleration (PGA) responsible for the damage of a building characterized by a vulnerability index Iv can be calculated from the relationship between the percentage of the building damaged by the earthquake ( $d$ : repair cost divided by the amount of money necessary to rebuild the whole building) and a lineal regression (Fig. 4c) which extremities are defined by the PGA that building would support without being damaged, $d=0$ (Eq. 2), and the PGA that would produce its collapse, $d=1$
(Eq. 3).

$$
\begin{aligned}
& \operatorname{PGA}_{(d=0)}=0.155 \exp [-0.0207(\mathrm{Iv}+25)] \\
& \operatorname{PGA}_{(d=1)}=\left[0.625+0.00029(\mathrm{Iv}+25)^{2.145}\right]^{-1}
\end{aligned}
$$

The applicability of the vulnerability index of Faccioli et al. (1999) to the building stock of Liège has already been discussed in the works of Jongmans and Plumier (2000) and Plumier et al. (2006). In those studies, the authors estimated a basic value of Iv for the different types of buildings usually found in this region, being the final Iv calculated for each building adding or subtracting several values representing the influence of some factors to their seismic vulnerability (Table 3 ). In the present study, we have recuperated this classification and used it to calculate a mean Iv for each damaged building located in Saint Nicolas.

\section{State of damage of the buildings after the 1983 earthquake}

To establish the statistical distribution of the damage caused by an earthquake to unreinforced masonry buildings in a given locality, it is necessary to use a common definition of the damage states applicable to all cases. In the present study, the degree of damage presented by the different buildings after the 1983 earthquake has been quantified using the damage scale defined by FEMA for the HAZUS programme (Kircher et al., 1997a) and their equivalences, according to Hill and Rossetto (2008), with the European Macroseismic Scale EMS-98 (Grünthal et al., 1998; Grünthal and Levret, 2001).

The different sources of information described in Sect. 3 of this paper do not allow determination of the statistical distribution of the damage in a geographical homogeneous way. In the case of the localities from which the amount 
of damaged chimneys was known (documents described as source (1) in Sect. 3), it was assumed that the proportion of damaged chimneys should be equivalent to the proportion of buildings presenting moderate and extensive damages ( $D 2 \leq D \leq D 3$ ) since, according to the EMS-98 macroseismic scale, chimneys begin to take damage from degree of damage $D 2$ (see Grünthal et al., 1998). This generalization is supported by the observation that higher degrees of damage due to the 1983 earthquake were rare and localized only in the localities of Saint Nicolas, Liège and Flémalle. Therefore, that assumption should be true for all localities but these three, which have been removed from dataset (1), because datasets (2), (3), (4) and (5) contain more detailed information on them. At the exception of these three localities, and due to the lack of more detailed data, we considered that the damage distribution was homogeneous at the scale of the locality.

The degree of damage of the individual buildings catalogued in the documents collected by the ROB from the Belgian Calamity Centre (described as source (5) in Sect. 3) and the ones sent by the city hall of Flémalle (described as source (3) in Sect. 3) could also be directly calculated from the brief descriptions of the damage and the repair needed after the earthquake included in those compilations. This permitted computation of the amount of buildings presenting each degree of damage per selected area and their geographical distribution over the locality of Flémalle as the document sent by the administration of this locality comprised all damaged buildings located in it. For the sake of comparison, we divided this locality into square areas of $200 \mathrm{~m} \times 200 \mathrm{~m}$ based on the maps discussed in the PSE-UL report (e.g. Fig. 3). A similar analysis was not possible for the data collected by the ROB (described as source (5) in Sect. 3) as this document contained descriptions only for some of the damaged buildings situated in different localities (mostly from Saint Nicolas). Nevertheless, these data were extremely useful to complement the information compiled in the PSEUL report and to characterize the damage state of individual buildings located in Saint Nicolas.

The evaluation of the damage states of the buildings situated in Saint Nicolas that were catalogued in the PSE-UL report (described as source (4) in Sect. 3) was a bit more difficult than for the buildings of Flémalle since no information is mentioned in that report on the nature of their damage. Instead, its authors quantified the intensity of the damage using the parameters repair cost (RC) and damage index (Id). These two parameters revealed themselves very useful to map geographically the intensity of the damage over this region (Figs. 3 and 4); nonetheless, they can be a bit ambiguous when used to quantify the degree of damage of a building. For instance, Id equal to 1 can indicate a damaged chimney or slight damages on internal walls or some broken fragile elements. In the same way, the RC due to a similar damage may be different from one building to another depending on the size of the house, architectural patrimony (restoration), number of floors, etc. Therefore, we decided to quantify the intensity of the damage using the damage states proposed by FEMA (1999) for the HAZUS fragility curve. With that purpose, we statistically analysed dataset (5), which already contained information on the RC and degree of damage of 113 buildings, as well as information enough to calculate their Id based on the codes shown in Table 1. Unfortunately no equation appeared to clearly relate the damage state either with the RC or with the Id. We established then the normal distributions of these parameters divided by the surfaces of the buildings for damage states SD, MD and ED in order to obtain the distribution of the RC per square metre. These calculations, although revealing a significant overlap (Fig. 5a), provided a first approach to establish roughly the interval of RC values where the degrees of damage SD, MD and ED should be located. During the previous calculation, it was also noticed that houses presenting degree of damage SD never needed repair costing more than $3 \%$ of the total cost of the house, while those in MD do not appear to exceed $21 \%$ of the building's value and the repair costs due to ED do not seem to be higher than $50 \%$ of the building's cost. These calculations were done assuming a mean cost of the habitable square metre in the region of Liège of $\sim 7500$ Belgian Francs (FB) at the event of the earthquake, about 186 present-day euros.

Comparing our observations with other correlations proposed in the literature to estimate the degree of damage from the $\mathrm{RC}$, it has been noticed that the RC intervals defining the different degrees of damage derived from our study are actually in good agreement with those discussed by Kircher et al. (1997b) and the RISK-UE project (Vacareanu et al., 2004). These two studies suggest that the RC of structural features presenting SD should not be higher than $2 \%$ of their replacement cost, that RC between 2 and $10 \%$ of the replacement cost would indicate MD, that 10 to $50 \%$ would suggest ED and that more than $50 \%$ of the cost would imply CD. We believe that the higher values obtained in the present study are probably because the repair cost assessed by the Belgian authorities for the buildings damaged by the 1983 earthquake included structural as well as non-structural damages. Therefore, we have decided not to apply the equivalences proposed in previous publications to distinguish between MD and ED in our study, considering the percentage of buildings presenting moderate and extensive damages together for all calculations, for we have not been able to separate them.

In order to refine the degree of damage evaluation of the buildings located in Saint Nicolas, we also compared the PSE-UL report with the information compiled by the regional fire brigade after the 1983 earthquake. This comparison revealed that 835 buildings appeared in both catalogues, adding new arguments to better establish the damage state for those buildings. According to the report of the fire brigade, it was established that a building whose degree of damage was debated between SD and MD would be assessed as MD if the fire brigade declared that repairs were needed 
a)

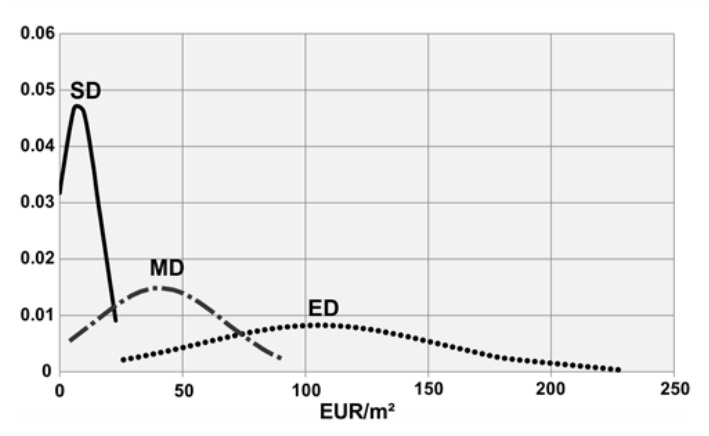

b)

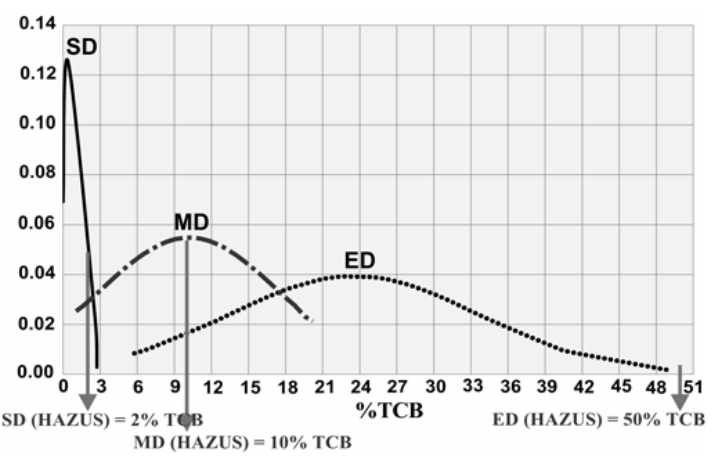

Fig. 5. (a) Normal distribution of repair cost (RC) divided by the surface of the buildings established for states of damage SD, MD and ED. (b) Normal distributions showing the percentage of the total cost of the building (TCB) represented by the RC estimated for states of damage SD, MD and ED. The highest values of the ranges proposed by Kircher et al. (1997b) for SD, MD and ED are indicated (HAZUS).

in the chimney and as SD if this feature was not affected. It was also decided that buildings declared uninhabitable by the fire brigade would have exhibited degrees of damage CD. In summary, we have evaluated the damage state of a building as slight $(D 1)$ when the RC did not exceed $3 \%$ of the building's value, providing that its chimney was not damaged; as moderate-extensive ( $D 2$ or $D 3$ ) when its $\mathrm{RC}$ was lower than $50 \%$ of the building's cost; and as complete damage ( $D 4$ or $D 5$ ) when its RC was higher than $50 \%$ of the cost of the house, or whenever the building was considered uninhabitable or marked to be demolished by the authorities. The documents provided by the ROB and fire brigade also permitted completion of the list of damaged buildings located in Saint Nicolas, with the inclusion of 58 buildings from the ROB catalogue and 55 buildings declared uninhabitable by the regional fire brigade that were not included in the original macroseismic study.

The complete list of damaged buildings situated in Saint Nicolas and Flémalle were geographically localized according to the maps provided by the PCRW (Portail Cartographique de la Region Wallonne: http://cartocit1.wallonie. be/pw/) and included in a similar grid to that defined in the PSE-UL report for Saint Nicolas and Liège localities (see Fig. 2). The percentage of buildings presenting degree of damage SD, MD-ED and CD were then established for each square of that grid after counting the total amount of buildings located in each of the different areas using street maps and aerial photographs. We also needed to recalculate the parameters TID and TRC (see Figs. 2 and 3) for all of the areas composing the grid of Saint Nicolas due to the inclusion of the 113 buildings from the ROB and fire brigade reports. These parameters could not be recalculated for the areas containing damaged buildings that were reported only by the regional fire brigade as their report did not include any information to estimate them. Fortunately, this was the case only for 27 squares of the grid defined for Saint Nicolas, ar- eas which were left out from all calculation including any of those parameters.

In the case of Liège, it was not possible to determine the amount of buildings presenting the different states of damage for any of the cells of the grid defined for this locality by the authors of the PSE-UL report as we had no information on the amount of damaged buildings located in any of the square areas. That report only included information on the minimum and maximum TID and TRC for each cell of the grid (see Figs. 2 and 3). In order to evaluate the damage and ground shaking in this locality, we extrapolated the results of statistical correlations between TID values and the percentage of buildings presenting damage states MD-ED revealed from the analysis of the data from Saint Nicolas (Fig. 6).

At the exception of the official inquiry done by the Royal Observatory of Belgium (source (1) in Sect. 3), we have no detailed information concerning the damage on individual houses for the localities of Seraing and Ans, which explains the gaps in the maps presented in Figs. 7 to 9. Detailed information on individual damaged buildings exits at the Belgian Calamity Centre, but retrieving them from the thousands of paper files archived in there would take years.

\section{Strong ground motion evaluations}

\subsection{Strong ground motions from fragility curves}

Based on the percentage of buildings presenting the different degrees of damage, mean response spectral accelerations (MRSA) could be calculated for each square of the grids dividing Flémalle and Saint Nicolas into square areas of $0.040 \mathrm{~km}^{2}$ applying, respectively, the HAZUS and Bsl fragility curves (Fig. $4 a$ and b). These curves were applied assuming that all damaged buildings can be classified as URML, even though a small amount of them had four or more storeys and were built in a mix of reinforced concrete and brick masonry. We were forced to do so because the total 

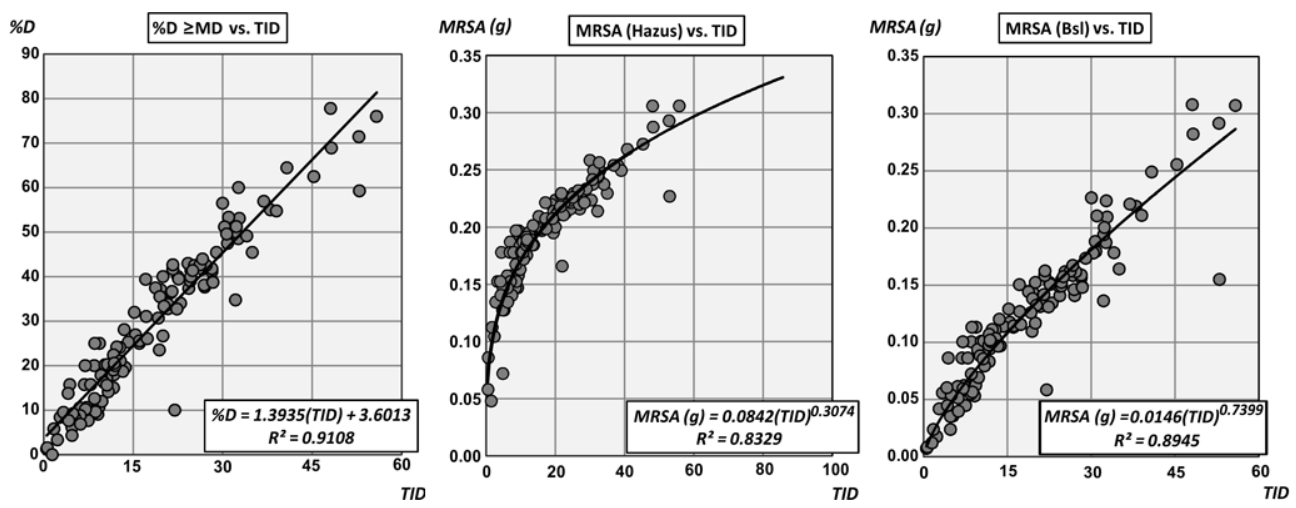

Fig. 6. Regression equations relating the total damage index (TID) with the percentage of buildings presenting moderate or larger degree of damage $(\% D \geq \mathrm{MD}$ ) and MRSA (period $\sim 0.3 \mathrm{~s}$ ) estimated from the HAZUS and Bsl fragility curves per square area of the grid defined for Saint Nicolas.

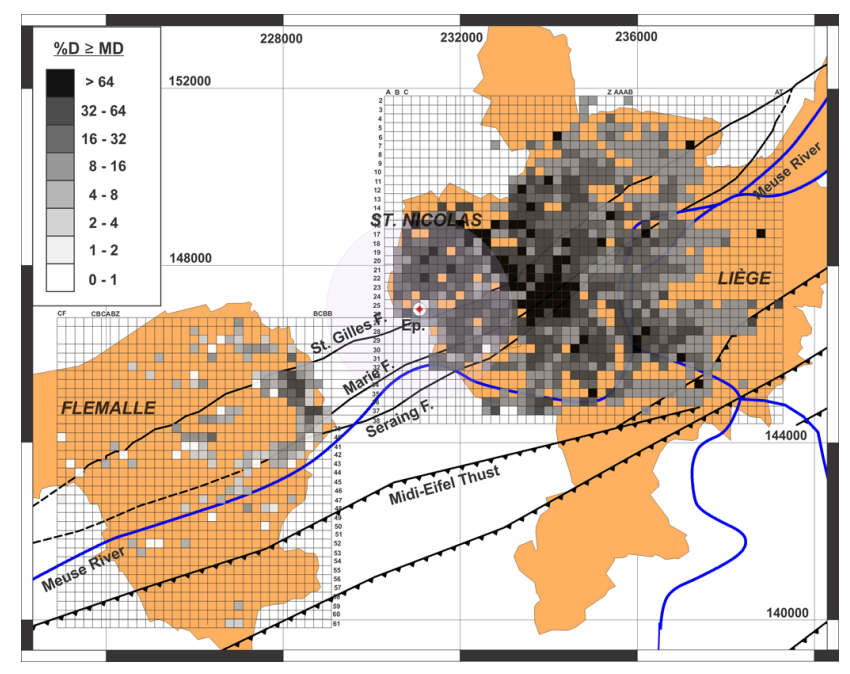

Fig. 7. Percentage of buildings presenting moderate or greater damages $(\% D \geq M D)$ after the 1983 Liège earthquake calculated for square areas of $0.040 \mathrm{~km}^{2}$ over the localities of Saint Nicolas, Liège and Flémalle. Projections: Belgian Lambert 72.

number of each type of building was not known, so it was impossible to estimate the percentage of buildings in the different degrees of damage for each of the building classes of this region. This assumption was made considering that, as seen in previous sections of this paper, the proportion of more-than-four-storey buildings with regards to the unreinforced masonry ones is extremely low in this area (less than $7 \%$ in Saint Nicolas), and therefore the error committed by including them among low-rise unreinforced masonry buildings (URML) should be negligible for the results of this study.

The application of these two fragility curves have shown that Sa estimated for a given area can differ significantly depending on the damage state used for its calculation. We believe that these differences are most probably due to the un-

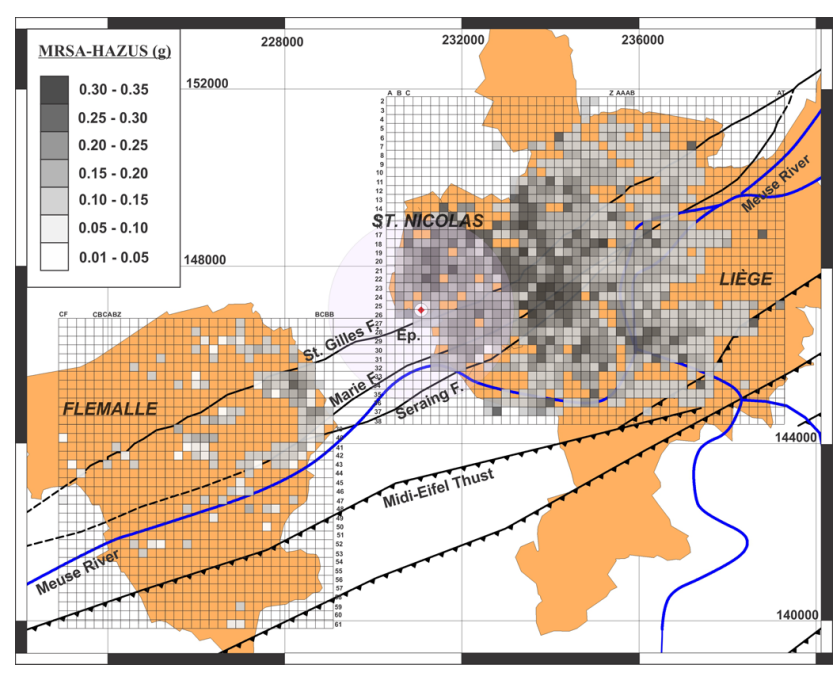

Fig. 8. MRSA (period $\sim 0.3 \mathrm{~s}$ ) distribution during the 1983 Liège earthquake estimated from the HAZUS fragility curve for square areas of $0.040 \mathrm{~km}^{2}$ over the localities of Saint Nicolas, Liège and Flémalle. Projections: Belgian Lambert 72.

certainty inherent to the fragility curves, as well as to the fact that many owners of the buildings having slight damages did not seek the help of the state as the money needed to repair their houses was not important. Furthermore, buildings reaching complete damage (CD) were rare during this event, therefore the percentage of buildings presenting those damages was negligible with regards to those having slight (SD), moderate (MD) and extensive (ED) damages. Consequently, in this study MRSA refers to the average of the median spectra accelerations obtained by applying the percentage of buildings characterized by MD plus ED to the different fragility curves, for all the cases where the percentage of buildings presenting MD-ED is equal to or greater than SD. Otherwise, MRSA indicates the median Sa value obtained according to the percentage of buildings in state of 


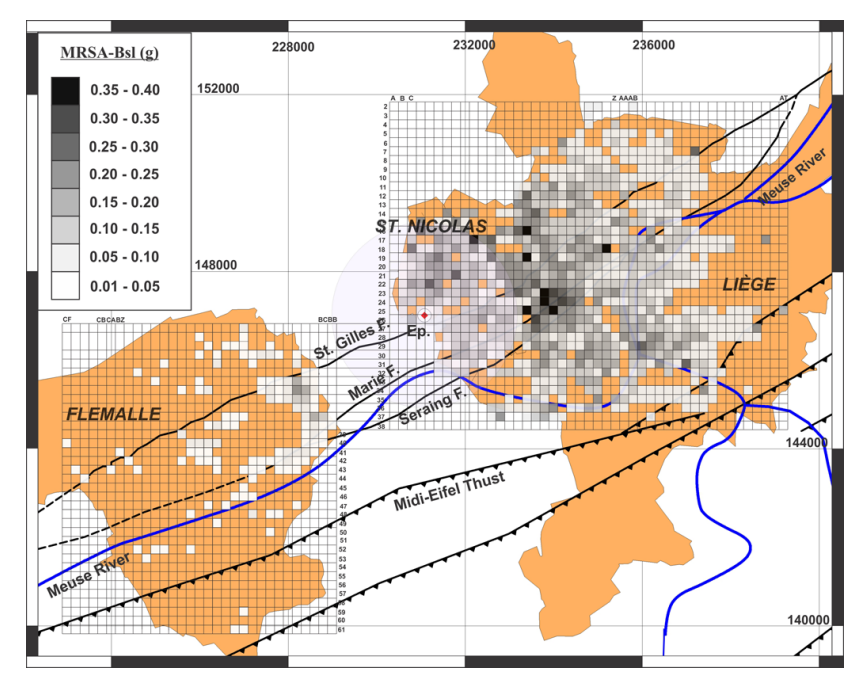

Fig. 9. Geographical distribution of MRSA (period $\sim 0.3 \mathrm{~s}$ ) during the 1983 Liège earthquake estimated applying Bsl fragility curve to the damaged building located in different square areas defined for the localities of Saint Nicolas, Liège and Flémalle. Projections: Belgian Lambert 72.

damage SD. Following this methodology, MRSA was calculated for all square areas of the grids defined for the localities of Flémalle and Saint Nicolas as well as for the rest of localities for which the percentage of damaged chimneys ( $D 2 \leq D \leq D 3$ ) was known. With regards to the locality of Liège, we did not have enough information to calculate MRSA from the damage. Hence, in order to establish the ground shaking affecting that locality during the 1983 earthquake, the parameters TID (total damage index) and TRC (total repair costs) calculated for the different square areas of Saint Nicolas were compared with the MRSA values obtained for each of those areas through the HAZUS and Bsl fragility curves. This comparison revealed a very good correlation between TID and the MRSA values obtained from the different fragility curves (Fig. 6). Consequently, by applying the equations derived from those correlations, and according to the mean values of TID showed in the maps included in the PSE-UL report, we were able to approximate an MRSA for each square of the grid defined for the locality of Liège. The results of this and the aforementioned calculations are plotted in Figs. 7 to 10 and will be discussed in the discussion section of this paper.

\subsection{Ground motions from the seismic vulnerability}

According to Faccioli et al. (1999), it is possible to evaluate the ground motion caused to a given building during an earthquake knowing the vulnerability index characterizing that building and the cost of the repairs (RC) that it needs afterwards (Fig. 4c). In order to apply this methodology to the building stock of Liège, it was therefore necessary to determine the Iv for each of the damaged buildings and their dam- age state in terms of RC. This methodology has only been applied to the locality of Saint Nicolas for only the PSE-UL report had enough information on the characteristics of the damaged buildings to estimate their Iv. Even though this information was quite limited - consisting of the age of the buildings, their relative position and their number of floors - it was enough to define a minimum and maximum Iv for most of the damaged buildings of this locality based on the classification presented in Table 3. In the present study, the Iv maximum of a given building is defined as its basic Iv plus all the influential factors that may increase its vulnerability (high percentage of open spaces, low-resistance ground floor, etc.), while Iv minimum will be equal to its basic Iv minus the possible factors that may decrease it (e.g. additional reinforcements) plus 5 since we consider that all the houses of this area will have at least one factor that will increase Iv (see Table 2). The damage $(d)$ caused to each of the buildings for which we were able to estimate Iv was calculated, following Faccioli et al. (1999) methodology, as the ratio between their repair cost and the cost to reconstruct the building entirely. The latter parameter has been calculated assuming that a one-storey house of $\sim 100 \mathrm{~m}^{2}$ per floor built in Liège at the time of the earthquake cost about 1.5 million FB ( $\sim 37184$ euro), which means about 7500 FB $(\sim 186$ euro) per habitable square metre. A mean PGA (MPGA) could then be estimated for most of the buildings listed in the PSE-UL report applying the relationship $d$-PGA-Iv shown in Fig. 4c and Eqs. (2) and (3). Finally, MPGA was estimated for each of the square areas defined for Saint Nicolas from the distribution comprising the maxima and minima values that were obtained for the damaged houses located in them.

MPGA calculated using Faccioli et al. (1999) methodology has been converted into MRSA using the equations recommended by the Eurocode 8 (Plumier et al., 2005) for natural periods of $\sim 0.3$ seconds and soils type E ( 5 to $20 \mathrm{~m}$ of soft sediment on top of rock), which is the one characterizing the region of Liège according to that publication. The results of this calculation have been plotted in Fig. 10 together with the results obtained from the fragility curves for Saint Nicolas, Liège and Flémalle, plus those estimated for the localities for which the percentage of damaged chimneys was known. The MRSA predicted for those locations according to the GMPE of Ambraseys et al. (1996) has been also indicated in that figure. We have chosen these GMPE because previous seismic risk and hazard studies performed in the region of Liège are based on them (e.g. Leynaud et al., 2000). A similar investigation could be done by considering other GMPEs, but the appeal of this comparison was to have an idea of the maxima accelerations expected in our study areas, and not to decide which GMPE performs better in this region. 

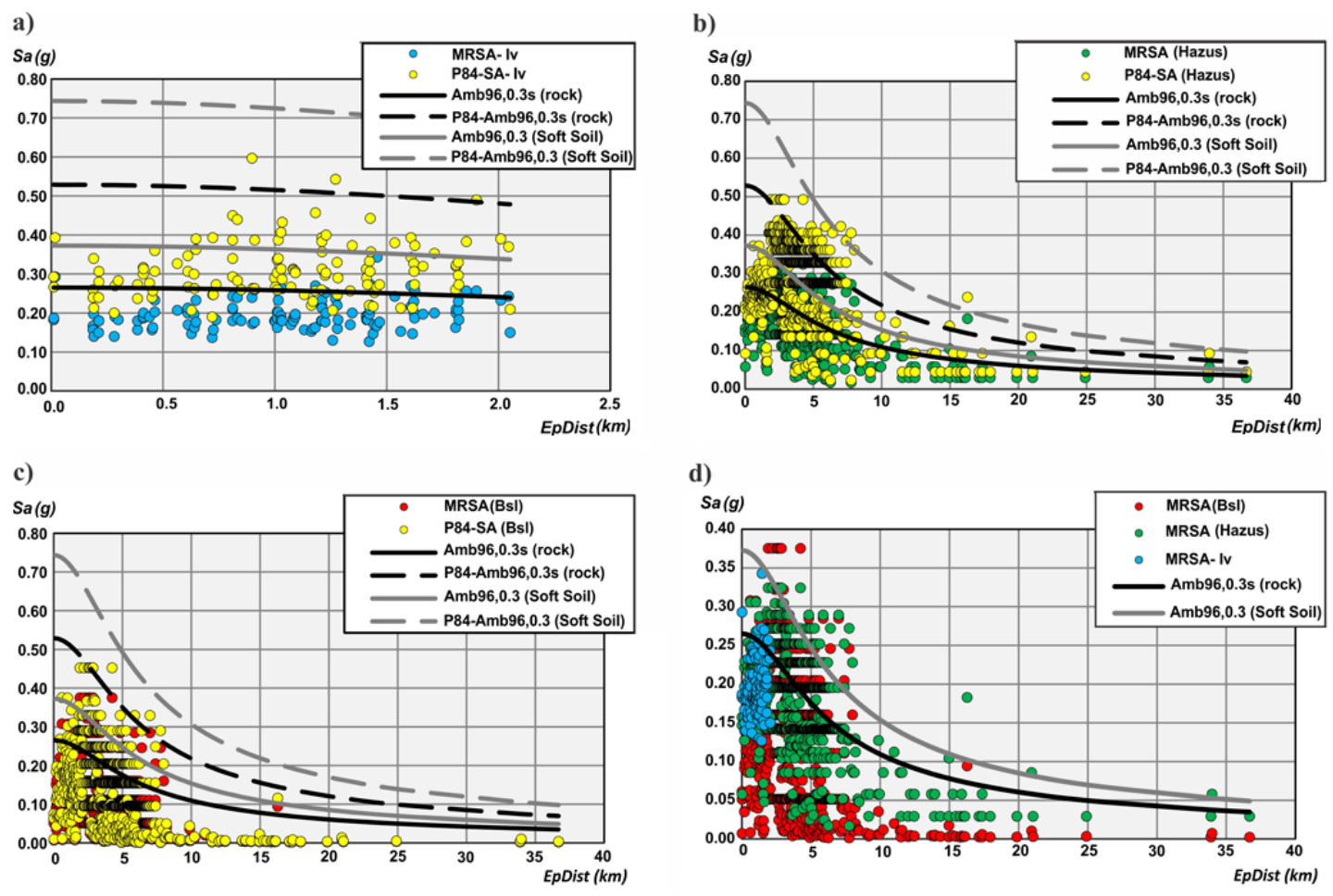

Fig. 10. MRSA and 84th percentile (period $\sim 0.3 \mathrm{~s}$ ) calculated at different epicentral distances applying (a) the indexed vulnerability method of Faccioli et al., (b) the HAZUS fragility curve and (c) the Bsl fragility curve. The last plot (d) compares the MRSAs calculated from all methodologies. MRSA and 84th percentile predicted by the GMPE of Ambraseys et al. (1996) for periods of $0.3 \mathrm{~s}$ for rock sites (black) and soft soils (dark grey) are indicated.

\subsection{Ground motion uncertainties from fragility and vulnerability curves}

The ground motions estimated using the methodologies exposed in the precedent sections of this paper are only an approximation and need to be taken carefully as they may be subjected to significant uncertainties. These uncertainties are due to the techniques on which fragility and vulnerability curves are based, as well as the application of these curves to the damage information available for this study. This is clear for the vulnerability method as PGAs are calculated according to linear regressions representing the best fit between the Iv of a given building, the percentage of damage caused to it and the PGA that may have produced the damage. Moreover, the lack of information on the characteristics of the damaged buildings catalogued in the different documents used to perform this study prevented the correct evaluation of their Iv. Therefore, the PGAs associated with the different squares of the grid in which Saint Nicolas was divided represent the median PGA (MPGA) calculated from the distribution of the possible maxima and minima Iv characterizing the different buildings located in those areas. That will indeed lead to significant uncertainties, which are probably greater than those inherent to the vulnerability curve itself. Hence, in this paper, the uncertainties associated with MRSAs estimated for a given area based on the Iv refer to the standard deviation of the distribution defined by the maxima and minima PGA established for each of the buildings located in it. This means uncertainties ranging between $0.05 g$ and $0.13 g$ per square area of Saint Nicolas.

With regards to the fragility curves, the curves representing each of the damage states are the median values of the damage distributions used to calculate them (Kircher et al., 1997a; Lang and Bachmann, 2004). Therefore, any acceleration estimated according to these fragility curves will be subjected to an inherent uncertainty equal to the standard deviation of the distribution from which the median value was calculated. This uncertainty is not specified for the values composing the curves of the different damage states; however, it can be assumed that the distribution of a given median value of any of the damage curves will have a standard deviation at least equal to the mean of the distance between that value and the one corresponding to the same amount of damaged buildings according to the curves nearby. That is, considering the HAZUS fragility curve, the MRSA associated with $40 \%$ of the buildings presenting slight damage will be equal to $\sim 0.16 \mathrm{~g}$ (intersection with the curve slight damage) plus/minus $0.015 \mathrm{~g}$, which is the value corresponding to the intersection with the curve modelling moderate damage $(0.19 g)$ minus $0.16 g$ and divided by 2 (see Fig. 4a). 
Considering that we have calculated the MRSA grouping moderate and extensive states of damage, the uncertainty will be equal to the sum of the standard deviations defined by each curve. This resulted in mean uncertainties of $\sim 0.05 \mathrm{~g}$ and $0.02 \mathrm{~g}$ for the HAZUS and Bsl fragility curves for the localities of Flémalle and Saint Nicolas. These uncertainties are obviously higher for the locality of Liège since there the MRSAs have been constrained extrapolating the results from Saint Nicolas. In that area, mean errors reach values of $0.13 \mathrm{~g}$ and $0.05 g$ for the HAZUS and Bsl fragility curves, respectively.

Another uncertainty to consider for this kind of analysis would be the one inherent to the application of these fragility curves to a group of buildings as even buildings classified as the same type may respond differently to similar accelerations. This may lead to differences in the percentage of buildings to which a specific damage was caused, and hence to an uncertainty in the estimation of the accelerations that affected them. In order to quantify this uncertainty, we have applied the two selected fragility curves to the damage information Pappin et al. (1994) collected after the $M_{\mathrm{w}} \sim 5.4$ (e.g. Van Eck and Davenport, 1994) earthquake that occurred in Roermond (the Netherlands) on 13 April 1992. In that study, Pappin et al. (1994) determined the percentage of brick-masonry buildings presenting degree of damage $D 1, D 2$ and $D 3$ located in several Dutch and German localities for three different periods of time: buildings built before 1920, between 1920 and 1960, and after 1960. In theory, if the fragility curves discussed in the present study model perfectly the response of brick-masonry buildings to horizontal accelerations, all the buildings of that type located in the same area should be damaged in a similar degree independently of their age (first assumption). In the same way, if these curves are accurate enough, the spectral accelerations calculated for a given area using them should be similar to one another independently of the degree of damage utilized for their calculation (second assumption).

In order to verify the first assumption, we calculated the proportion of buildings for each period of time discussed in Pappin et al. (1994) presenting degree of damage D1 with respect to the total survey size of each locality. We obtained that, on the one hand, the amount of buildings constructed before 1920 presenting degree of damage $D 1$ are on average $6 \%$ more abundant than those in the same state of damage built in between 1920 and 1960. On the other hand, the percentage of buildings constructed in 1920-1960 having a state of damage $D 1$ is about $3 \%$ greater than those built after 1960. Assuming that $D 1$ in Pappin et al. (1994) is equivalent to slight damage (SD) in HAZUS, we estimate mean errors of $0.03 g(D 1 \pm 3 \%)$ and $0.04 g(D 1 \pm 6 \%)$ for the MRSA calculated from the HAZUS fragility curve, and of less than $0.01 \mathrm{~g}$ for the Bsl curve. Regarding the second assumption, the total proportion of buildings presenting degrees of damage $D 1$ and $D 2$ were calculated for each locality by adding all the buildings that presented each of those degrees of dam- age independently of their age. MRSA was then estimated according to the percentage of buildings in a damage state $D 1$ and $D 2$ for each locality by applying both fragility curves and considering that $D 2$ in Pappin et al. (1994) is equivalent to moderate damage. The comparison of these values showed mean differences between the accelerations calculated from $D 1$ and $D 2$ of $\sim 0.03 g$ and $\sim 0.01$ for the HAZUS and Bsl curves, respectively. In summary, the uncertainties due to the application of these fragility curves to a group of buildings appear to be relatively low if we compare with the uncertainties discussed above.

\section{$7 \quad$ Discussion and conclusions}

The geographical distribution of the accelerations produced by the 1983 Liège earthquake approximated using the fragility curves and the vulnerability index method discussed in this paper correlates reasonably well with the spatial distribution of the total repair cost (TRC) and total damage index (TID) shown in the PSE-UL report (compare Figs. 2, 3, 7 and 8), which is not unexpected as these parameters have been deduced from the same original dataset. The highest accelerations seem to be generally concentrated to the north and east of the microseismic epicentre, especially along a $2 \mathrm{~km}$ elongated NW-SE strip near the Saint Nicolas-Liège boundary. In those locations, maxima Sa (percentile 84) estimated from the damage range between 0.45 and $0.6 \mathrm{~g}$. That is, according to the equations proposed in the Eurocode 8 (Plumier et al., 2005), PGAs of 0.13-0.2 $g$, corroborating the ground motions proposed by Plumier (1985) and Camelbeeck (1985) for the epicentral area of the 1983 earthquake. The concentration of the damage in those locations has already been noticed, among others, by Jongmans and Campillo (1984), who attributed the shape of the damaged zone to a directivity of the seismic amplifications due to the location of this zone in a regional syncline. It has also been observed that the highest values of TID, TRC, MRSA and percentage of buildings presenting moderate or higher damages are concentrated in an area located $3 \mathrm{~km}$ to the east of the microseismic epicentre. This area coincides with a thick package of colluvium sediments deposited following the curve of the Meuse River, as was already noticed by Jongmans (1989). In short, the geographical distribution of the MRSA, TID and TRC during the 1983 Liège earthquake appears to be a good indicator of how an earthquake of these characteristics would affect the different areas of the studied localities, and therefore it may be an invaluable tool to assess the seismic risk of the Liège area. Indeed, the black and dark-grey zones presented in Figs. 2 and 3 and in Figs. 7 to 9 will probably represent some of the areas with highest seismic risk and thus places to which the emergency services should pay special attention if another earthquake occurs in this region. Especially dangerous would be the area where the colluvium is situated, where more than $60 \%$ of the buildings might have presented 
a moderate or higher degree of damage caused by the 1983 Liège earthquake (Fig. 7).

With regards to the ground motions estimation, it is observed that the results from both fragility curves and the vulnerability-indexed methodology are in good agreement with one another. However, $\mathrm{Sa}$ in the areas with a lower percentage of buildings presenting moderate or greater degree of damage obtained from the Bsl curve are generally lower than the ones estimated by the other techniques (see Figs. 8 and 10d). The HAZUS fragility curve suggests $0.3 \mathrm{~s}$ MRSA ranging from 0.02 to $0.35 \mathrm{~g}$ for the epicentral area of the 1983 earthquake $(0-3 \mathrm{~km})$, with most of the values being in between 0.1 and $0.3 \mathrm{~g}$. This is not far from the MRSAs calculated using Bsl and Faccioli et al. (1999) curves, which suggest MRSA for the same area of 0.004-0.39 $g$ and $0.13-0.34 \mathrm{~g}$, respectively. As a matter of fact, the ground motions obtained by applying the different methodologies discussed in this study match reasonably well the Sa predicted by the GMPE of Ambraseys et al. (1996) for the different areas affected by the 1983 Liège earthquake: zones presenting maxima Sa according to the fragility and vulnerability curves (e.g. colluvium zone) coincide with the values expected in those locations by the GMPE for soft soil sites, while the Sa calculated for other sites are generally equal or lower to those predicted by Ambraseys et al. (1996) for rock environments (see Fig. 10).

The good agreement between the ground motions estimated from the discussed vulnerability and fragility curves and those predicted by one of the GMPEs commonly used in northwestern Europe lead us to believe that these vulnerability and fragility curves model reasonably well the building behaviour in the case of the 1983 Liège earthquake. This result would thus validate the use of fragility and vulnerability curves in seismic risk evaluations of the old industrial cities of northwestern Europe, as was already suggested in the preliminary seismic risk study performed in Liège by Jongmans and Plumier (2000) by using the vulnerability method of Faccioli et al. (1999). Of course, the ground motion estimations proposed in this study have been calculated using fragility and vulnerability curves that were not developed specifically for the building stock of Liège. Therefore, even though the results of the present study agreed with the GMPE predictions, it would be interesting to test numerically a typical building of Liège under the excitation of representative accelerograms to confirm the validity of the fragility and vulnerability curves for the considered building stock. Even if such computations have not yet been done with this specific purpose, numerical modelling (Plumier et al., 2005) and shaking table tests (Degée et al., 2008) have been conducted on non-engineered masonry buildings typical of this part of Europe by proposing scenarios coherent with the results of the present study. For instance, based on the experience of the damage caused by the 1983 Liège earthquake, Plumier et al. (2005) studied numerically the structural resistance of non-engineered buildings typically found in that region with the purpose of defining the elements to reinforce these masonry dwellings against earthquakes represented by an EC-8 elastic response spectrum with a $0.1 \mathrm{~g}$ PGA, agreeing with the maxima PGAs expected in this area according to our study.

\section{Supplementary material related to this article is available online at: http://www.nat-hazards-earth-syst-sci.net/13/1983/2013/ nhess-13-1983-2013-supplement.zip.}

Acknowledgements. We thank Denis Jongmans for providing us with the numerous data that he collected at the event of the Liège earthquake, André Plumier for supplying the seismic risk reports of Liège, Anne-Marie Barszez for her work compiling the files from the Belgian Calamity Centre and Alain Sabbe for his support of this study. Thanks also go to the Portail Cartographique de la Region Wallonne for providing the maps and aerial photographs of the region of Liège. We also thank Ronald Van der Linden, director of the Royal Observatory of Belgium, for his unconditional support of this study.

Edited by: S. Tinti

Reviewed by: P. T. Karantoni and one anonymous referee

\section{References}

Ahorner, L. and Pelzing, R.: The source characteristics of the Liège Earthquake on November 8, 1983, from digital recordings in West Germany, in: Seismic activity in Western Europe, edited by: Melchior, P. D., Reidel Publishing Company, 263-289, 1985.

Ambraseys, N. N., Simpson, K. A., and Bommer, J. J.: Prediction of horizontal response spectra in Europe, J. Earthq. Eng. Struct. Dynam., 25, 371-400, 1996.

Berz, G.: Assessment of the losses caused by the 1992 Roermond earthquake, the Netherlands (extended abstract), Geologie en Mijnbouw, 73, 281 pp., 1994.

Camelbeeck, T.: Etude Microséismique du séisme de Liège du 8 Novembre 1983, Estimation du "strong ground motion", in: Le séisme de Liège et ses implications pratiques, edited by: Breesch, L., Camelbeeck, T., De Becker, M., Gurpinar, A., Monjoie, A., Plumier, A., and Van Gils, J. M., Annales des travaux publics de Belgique, no 4, 1985.

Camelbeeck, T.: Mécanisme au foyer des tremblements de terre et contraintes tectoniques: le cas de la zone intraplaque belge, Ph.D. thesis, Université Catholique de Louvain, 1993.

Camelbeeck, T., Alexandre, P., Vanneste, K., and Meghraoui, M.: Long-term seismicity in regions of present day low seismic activity: the example of Western Europe, Soil Dynam. Earthq. Eng., 20, 405-414, 2000.

De Becker, M.: L'enquête macroséismique du séisme de Liège du 8 novembre 1983, in: Le séisme de Liège et ses implications pratiques, edited by: Breesch, L., Camelbeeck, T., De Becker, M., Gurpinar, A., Monjoie, A., Plumier, A., and Van Gils, J. M., Annales des travaux publics de Belgique, no 4, 1985. 
Degée, H., Denoel, V., Candeias, P., Campos-Costa, A., and Coelho, E.: Experimental investigation on non-engineered masonry houses in low to moderate seismicity areas, in: Proceedings of the 14th World Conference on Earthquake Engineering, Beijing, China, 8 pp., 2008.

Ebel, J. E.: The Cape Ann, Massachusetts Earthquake of 1755: A 250th Anniversary Perspective, Seismol. Res. Lett., 77, 74-86, 2006.

Faccioli, E., Pessina, V., Calvi, G. M., and Borzi, B.: A study on damage scenarios for residential buildings in Catania city, J. Seismol., 3, 327-343, 1999.

Federal Emergency Management Agency (FEMA): Earthquake loss estimation methodology earthquake HAZUS99 Service Release 2 (SR2) technical manual, Washington, 1999.

Grünthal, G. and Levret, A. (Eds.): L'Echelle Macrosismique Européenne. European Macroseismic Scale 1998 (EMS-98), Cahiers du Centre Européen de Géodynamique et de Séismologie 19, Centre Européen de Géodynamique et de Séismologie, Luxembourg, 103 pp., 2001.

Grünthal, G. (Ed.), Musson, R., Schwarz, J., and Stucchi, M.: European Macroseismic Scale 1998 (EMS-98), Cahiers du Centre Européen de Géodynamique et de Séismologie, 15, 101 pp., 1998.

Hill, M. and Rossetto, T.: Comparison of building damage scales and damage descriptions for use in earthquake loss modeling in Europe, Bull. Earthq. Eng., 6, 335-365, 2008.

Jongmans, D.: Les Phénomènes d'amplification d'ondes sismiques dus a des structures geologiques, Annales de la Société géologique de Belgique, 112, 369-379, 1989.

Jongmans, D. and Campillo, M.: Répartition des dommages pendant le tremblement de terre de Liège du 8 Novembre 1983: Effet de source et effet de site. Colloque national de génie parasismique sur les mouvements sismiques pour l'ingénieur, St. Rémy les Chevreuses, 16 mars 1988, 2.23-2.33, 1984.

Jongmans, D. and Plumier, A.: Etude pilote du risque sismique sur une partie de la ville de Liège $\left(4 \mathrm{~km}^{2}\right)$, Internal Report, Faculté des Sciences Appliquées, Université de Liège, 2000.

Kircher, C. A., Nassar, A. A., Kustu, O., and Holmes, W. T.: Development of building damage functions for earthquake loss estimation, Earthq. Spectra, 13, 663-682, 1997a.

Kircher, C. A., Reitherman, R. K., Whitman, R. V., and Arnold, C.: Estimation of Earthquake Losses to buildings, Earthq. Spectra, 13, 703-720, 1997b.

Kochkin, V. G. and Crandell, J. H.: Survey of historic buildings predating the 1811-1812 New Madrid earthquake and magnitude estimation based on structural fragility, Seismol. Res. Lett., 75, 22-35, 2004.

Lang, K. and Bachmann, H.: On the seismic vulnerability of existing buildings: a case study of the city of Basel, Earthq. Spectra, 20, 43-66, 2004.

Leynaud, D., Jongmans, D., Teerlynck, H., and Camelbeeck, T.: Seismic hazard assesment in Belgium, Geologica Belgica, 3, 67$86,2000$.
Monjoie, A.: La géologie de la région liégeoise et le tremblement de terre du 8.11.1983, in: Le séisme de Liège et ses implications pratiques, edited by: Breesch, L., Camelbeeck, T., De Becker, M., Gurpinar, A., Monjoie, A., Plumier, A. and Van Gils, J. M., Annales des travaux publics de Belgique, 4, 1985.

Murty, C.: Learning earthquake design and construction 12, How do Brick Masonry houses behave during Earthquakes?, Resonance, 10, 88-90, 2005.

Newmark, N. M. and Hall, W. J.: Earthquake spectra and design, Engineering monographs on earthquake criteria, structural design, and strong motion records, vol 3. Earthquake Engineering Research Institute, University of California, Berkeley, CA. 8/5, 1982.

Pappin, J. W., Coburn, A. R., and Pratt, C. R.: Observations of damage ratios to buildings in the epicentral region of the 1992 Roermond earthquake, the Netherlands (extended abstract), Geologie en Mijnbouw, 73, 299-302, 1994.

Plumier, A.: Les effets sur les constructions, Les réparations, in Le séisme de Liège et ses implications pratiques, edited by: Breesch, L., Camelbeeck, T., De Becker, M., Gurpinar, A., Monjoie, A., Plumier, A., and Van Gils, J. M., Annales des travaux publics de Belgique, no 4, 1985.

Plumier, A., Doneux, C., Camelbeeck, T., Van Rompaey, G., Jongmans, D., Wathelet, M., Teerlynck, H., and Nguyen, F.: Seismic risk assessment and mitigation for Belgium in the frame of EUROCODE 8: final report, Brussels, Federal Science Policy, (SP1481), 2005.

Plumier, A., Camelbeeck, T., and Barszez, A.-M.: Le risque sismique et sa prévention en région Wallonne, in: Les risques majeurs en Région Wallonne. Prévenir en aménageant, Aménagement et Urbanisme, vol. 7 - Direction générale de l'Aménagement du territoire du logement et du patrimoine (DGATLP), 240-273, 2006.

RISK-UE BEE special edition: RISK-UE project special edition, Bull. Earthq. Eng., 4, 319-463, 2006.

Rota, M., Penna, A., and Magenes, G.: A methodology for deriving analytical fragility curves for masonry buildings based on stochastic nonlinear analyses, Eng. Struct., 32, 1312-1323, 2010.

Spence, R. J. S., Coburn, A. W., and Pomonis, A.: Earthquake Engineering, Tenth World Conference, Balkema, Rotterdam, ISBN $9054100605,1992$.

Vacareanu, R., Lungu, D., Aldea, A., and Arion, C.: An advanced approach to earthquake risk scenarios with applications to different European towns, Report WP7: Seismic Risk Scenarios Handbook, European Commission, Brussels, 2004.

Van Eck, T. and Davenport, C. A. (Guest Eds.): Special Issue, Seismotectonics and seismic hazard in the Roer Valley Graben; with emphasis on the Roermond earthquake of April 13, 1992, Geologie en Mijnbouw, 73, 441 pp., 1994. 